\title{
smartEducation: Developing Stress Management and Resiliency Techniques
}

\author{
Karen Ragoonaden
}

\begin{abstract}
smartEducation (Stress Management and Resiliency Techniques) is a mindfulness-based professional learning initiative positioned in a Faculty of Education of a Western Canadian university. Following similar evidence-based initiatives of mindfulness in education, the smartEducation curriculum comprises nine sessions offered in a variety of face-to-face, intensive, and blended formats. This renewal program supports the development of self-care techniques to cultivate personal and professional resilience through a greater understanding and control of breath, movement, and the physiology of emotions. The 20-hour program consists of eight two-hour sessions and a four-hour silent retreat. This article provides an overview of the research supporting mindfulness in education and presents the results of a pilot study conducted with preservice teachers enrolled in the smartEducation course.
\end{abstract}

\section{Background}

Research has indicated that teachers play an integral role in nurturing and in creating environments that support social, emotional, and academic growth in students (Lantieri \& Nambiar, 2012; Oberle \& Schonert-Reichel, 2016; Palmer 1998; Roeser, Skinner, Beers, \& Jennings, 2012). Understanding the pivotal role of the teacher in the classroom, it is troubling to note that the literature estimates that between $30-50 \%$ of Canadian teachers are leaving their classrooms within the first five years due to occupational stress and burnout issues related to emotional exhaustion, heavy workloads, lack of support, and difficulties to form close relationships with their students (Karsenti \& Collin, 2013; Montgomery \& Rupp, 2005; Oberle \& Schonert-Reichel, 2016; Roeser et al., 2012). The detrimental effects of an acquired, chronic stress disorder on personal and professional well-being are well-documented (Jennings \& Greenberg, 2009; Meiklejohn et al., 2012; Schonert-Reichl \& Lawlor, 2010; Taylor et al., 2015). These empirical studies also identify variables such as a lack of available support systems and the presence of minimal resources in the workplace as primary stressors influencing health and well-being. Acknowledging that stressors affect teachers' capacity to create a positive learning environment, increased attention is being given to professional learning initiatives which support and nurture the cultivation of mindfulness skills like focused attention, mental flexibility, emotion regulation, resilience, empathy, forgiveness, and compassion (Jennings \& Greenberg, 2009; Jennings, Lantieri, \& Roeser, 2010; Roeser et al., 2012; Taylor et al., 2015).

Recognizing that mindfulness is a predictor of psychological well-being, quality of life, and lowered stress experience, mindfulness-based interventions (MBIs) represent emerging innovative professional learning 
initiatives aimed at improving personal and professional practices (Baer, Lykins, \& Peters 2012; Brown \& Ryan 2003; Lykins \& Baer 2009; Ragoonaden, 2015; Ragoonaden \& Bullock, 2016; Roeser et al., 2013). Despite the abundant literature illustrating unique and inclusive ways of fostering mindfulness in education, the challenges of implementing these practices are numerous. Efforts to do so in educational contexts have been slow and are strife with concerns regarding personal and professional sustainability as well as the fiscal viability of these initiatives.

Initial resistance to mindfulness initiatives in educational contexts can be traced to the historical tenets of practices originating in Eastern contemplative traditions, specifically Buddhist epistemology and spiritual traditions. Cullen (2011) recognizes that most Western meditation arises from the Theravada branch of Buddhism, Vispassana. As the practice of insight, Vispassana incorporates the seminal Four Foundations of Mindfulness focusing on the cultivation of awareness of body, feelings, mental states, and mental contents.

Notwithstanding the current culture of situating all aspects of mindfulness as a panacea for stress management, an informed and sustained awareness of the history, language, images, metaphors of, not only Eastern, but also inclusive of Western contemplative practices, would optimize the well-recorded benefits of cultivating awareness of the body, heart, and mind (McCown, Reibel, \& Mecozzi, 2010).

In keeping with the division between State and Church, at a purely secular level, Mindfulness has entered into contemporary consciousness through the work of Jon Kabat-Zinn (PhD) who adapted his own Buddhist meditation practice for his clinical patients. Named Mindfulness-Based Stress Reduction (MBSR), this clinical intervention was designed for cancer patients dealing with intense pain and suffering. The formal practices in MBSR are

mindful movement (gentle hatha yoga with an emphasis on mindful awareness of the body); the body scan (designed to systematically, region by region, cultivate awareness of the body-the first foundation of mindfulness - without the tensing and relaxing of muscle groups associated with progressive relaxation); and sitting meditation (awareness of the breath and systematic widening the field of awareness to include all four foundations of mindfulness: awareness of the body, feeling tone, mental states and mental contents). (Cullen, 2011, p. 3)

Forty years of research on MBSR has demonstrated that this course of action provides benefits in a number of areas like anxiety, depression, chronic pain, immune system function, heart disease, substance abuse, eating disorders, and improving attention skills (Davidson et al., 2003; Ludwig \& Kabat-Zinn, 2008). MBSR has been repeatedly documented to be effective in treating mental health problems, particularly depression and anxiety, in numerous adult populations (Greeson, 2009). Prompted by the robust scientific findings of mindfulness as a tool to support physical and mental health in adult populations, pedagogical institutions are taking note: teachers are enrolling in mindfulness training programs, administrators are introducing mindfulness to their schools, and researchers are devising ways to evaluate the effects of mindfulness in cohorts of students and teachers (Mackenzie, 2015; Meiklejohn et al., 2012; Saltzman, 2012). Consequently, revised versions of MBSR aimed at fostering sustainable practices designed to promote resiliency and well-being in a variety of therapeutic and pedagogical contexts have 
emerged. These include Acceptance and Commitment Therapy (ACT), Mindfulness-Based Cognitive Therapy (MBCT), and smartEducation (stress management and resilience techniques in Education). In an attempt to distinguish between MBSR-based therapeutic interventions and MBSR-based pedagogical initiatives, the focus of this article will be on smartEducation, the Canadian version of the American, SMARTINEDUCATION.

\section{What Is smartEducation?}

smartEducation is a derivative of the original curriculum, SMARTinEDUCATION (Stress Management and Relaxation Techniques in Education). Developed by Cullen and Wallace (2010), this 36-hour mindfulness-based course, funded by the Impact Foundation and Passageworks in Colorado, has been the subject of several research studies which revealed positive findings supporting the benefits of mindfulbased interventions in reducing stress and promoting emotional resilience in teachers.

For example, Benn, Akiva, Arel, and Roeser (2012) led a randomized controlled study on the effects of mindfulness training on educators and parents of children with special needs. Their findings indicated that SMARTinEDUCATION mindfulness training "significantly influenced caregiving competence specific to teaching" (p. 1476) and significant reductions in stress and anxiety, as well as increased mindfulness, self-compassion, personal growth, empathic concern, and forgiveness. Roeser et al. (2013) examined the psychological and physiological effects on 113 teachers in Canada and the U.S. of randomized assignation to an eight-week Mindfulness Training (SMARTinEDUCATION). Results showed teachers assigned to mindfulness training (MT) showed greater mindfulness, focused attention, working memory capacity, occupational self-compassion, as well as a reduction in symptoms related to occupational stress, burnout, anxiety, and depression. Abenavoli, Jennings, Greenberg, Harris, and Katz (2013) researched 64 educators using self-reports measures of mindfulness, burnout, sleep-related impairment, daily physical symptoms, and stress demonstrating that the teachers' mindfulness practices had a strong protective effect against burnout. Flook, Goldberg, Pinger, Bonus, and Davidson (2013) led a randomized control pilot trial of a modified Mindfulness Based Stress Reduction course adapted specifically for teachers. Similarly, their results suggest that the course may be a promising intervention with participants showing significant reductions in psychological symptoms and burnout and increases in self-compassion. In particular, Jennings et al. (2010) explored how mindfulness, self-compassion, personal efficacy, and positive affect were associated with being better able to offer emotional support to challenging students. An overview of these studies offers the rationale to better understand how mindfulness-based practices incorporated into teacher professional learning programs, including Teacher Education, can support social and emotional competence, consequently improving learning environments. Showing strong support in emergent literature, the above studies demonstrate the rationale for examining MBls for educators (Frank, Jennings, \& Greenberg, 2013; Roeser et al., 2013; Poulin, Mackenzie, Soloway, \& Karayolas, 2008; Taylor et al., 2015). An important extension of this rationale includes positioning MBIs as accessible and sustainable professional learning models for both preservice and service teachers. 


\section{smartEducation as Professional Learning to Foster Health and Well-Being}

Coined in the 1990s, professional learning was conceptualized to promote more active forms of knowledge mobilization (Lieberman, 1995; Zeichner, 1995). Specifically, professional learning constitutes the processes that teachers are engaged in when they expand, refine, and change their practice (Kaser \& Halbert, 2009; Mockler, 2013; Timperley, 2008). At its crux, professional learning supports a shift away from the neoliberal-laced concept of professional development revolving around the technical upskilling of teachers and acquisition of policy-mandated techno-rational, and punctual knowledge (Mockler, 2005). Progressing towards a self-aware discourse of professional learning where teacher agency is respected, this paper suggests that the value of introducing and developing innovative, sustainable habits of mind supported by mindfulness practices are important components in supporting and nurturing health and well-being.

As a further attribute to the dissemination of mindfulness training (MT) for educators, Mackenzie (2015) summarizes the plethora of research which suggests that MBls can enhance cognitive skills, brain function, immune system function, emotional regulation, stress resiliency, as well as pro-social behavior and communication skills in professional and personal contexts. Neuroscience has offered compelling evidence to support the use of mindfulness practices in professional contexts. Scientific studies show that mindfulness training develops one's concentration, attention, executive function (planning, decision making, and impulse control), emotional balance, pro-social behavior, compassionate action, and promotes mental well-being (Ragoonaden, 2015). The regular practice of mindfulness-based initiatives, introduced as professional learning in pedagogical contexts, has the potential to revitalize purpose, improve achievement, and to foster positive interpersonal communication and relationships.

\section{Mindful Practices in Educational Contexts}

Using a logic model and theory of change, researchers examining Mindfulness practices in educational contexts, Roeser and colleagues (2013) recognized the positive effects of MT on teachers who improve practice and the ensuing indirect effects on students who learn more effectively. In their seminal white paper, Mieklejohn et al. (2012) suggest that personal training in mindfulness skills can increase teachers' sense of well-being and teaching self-efficacy, as well as their ability to manage classroom behavior and establish and maintain supportive relationships with students. It is for this reason that this paper supports the literature situating mindfulness as professional learning. Responding to the noted efficacy of MT, the 36-hour SMARTinEDUCATION was revised into a more accessible 20-hour smartEducation professional learning course focusing on an experiential approach to stress reduction and emotional resiliency. As a support for the home practices, a smartEducation participant booklet was conceptualized (smartEducation Participant Booklet, 2015). In a response to requests from the Health sector, the smartEducation curriculum has undergone minor content changes representative of interest from Faculties of Nursing and Social Work.

As indicated, smartEducation is an eight-week initiative based on MBSR and grounded in principles and applications to improve and sustain health and well-being. The extensively researched MBSR serves as 
its foundation ( $70 \%$ of the program content) along with theoretical framings of emotion (20\%) and forgiveness and compassion theories (10\%). The aim of the program is to manage stress through the acquisition of skills leading to a greater understanding and awareness of emotions in self and others, creating emotional balance and improving health and well-being. Exposure to and guided practices support the development of self-care techniques to cultivate personal and professional resilience using empathy, kindness, and compassion. This, in turn, creates effective strategies for relating to challenging situations by promoting discernment, concentration, attention, and awareness. Curricular components, supported by guided practices and practice logs, include:

- Introduction to Practice

- Practice

- Reacting versus Responding (stress)

- Emotions

- Anger

- Forgiveness

- Silent Retreat

- Kindness and Empathy

- New Beginnings

\section{Silence}

An important component of the smartEducation course is the four-hour Silent Retreat. Why a Silent Retreat? In the hyperactivity and hyper-connectedness of society, silence has many benefits. As our intellectual and emotional lives calm down, and turn to silence, our bodies relax. Emotions that are activated by talking and listening settle into a type of homeostasis, a balance. In sustained silence, our senses become more acute and tune in to quieter thoughts and an expanded awareness of our emotional and physical selves and of our environment (Moran, William, \& Heatherton, 2013). An important component of the learning of resiliency techniques in smartEducation are the guided experiential activities done in silence: secular meditation, kindness and forgiveness meditations, emotional and physical awareness, and mindful movement. Weekly sessions involve guided practices, sharing circles, and mindful listening and brief didactic overviews related to the science behind the practices. Using practice logs and having access to guided practices, participants are encouraged to develop sustainable daily mindful habits with the goal to improve personal, emotional, mental, and physical health. The guided practices below provide examples of the mindfulness techniques introduced to participants. (See: https://education.ok.ubc.ca/research/smartineducation.html)

\section{Benefits of smartEducation}

As an antidote to the frenetic pace of contemporary life, each of the nine smartEducation sessions encourages the exploration of individual pathways and addresses the challenges of being present, aware, and non-judgmental in hyper-connected, hyper-paced professional contexts where burn-out, competition, anxiety, and isolation abound. It is of note that smartEducation is a non-religious and non- 
sectarian course delivered by accredited facilitators. Seminal concepts of kindness, compassion, forgiveness, attention, intention, and authenticity as pathways to well-being are the core foundations of this course and support the well-being of teachers affecting the prosocial nature of contemporary schooling.

\section{The Pilot Study}

In order to study the implementation of MT as a potential pathway in professional learning and in Teacher Education, a pilot study was conducted in Winter 2016. Taking place in Western Canada, all preservice teachers $(n=60)$ in an elementary Teacher Education program were invited to participate in the 20-hour smartEducation program. This occurred outside the realm of their regular program of study and was positioned as a professional learning initiative. Data collection included a self-reported survey, selfreported practice logs and an assignment relating to their experiences in smartEducation. The descriptive pre and post results of the Five Factor Mindfulness Questionnaire (FFMQ) and a qualitative analysis of the practice logs and the assignment are presented. We sought to replicate prior work demonstrating the progression of educators' mindfulness as well as indicators of daily functioning mediated by the effects of mindfulness.

\section{Participants}

Subsequent to the invitation to participate in the smartEducation course offered through January-March 2016, 19 preservice teacher educators (88 per cent female) responded. On average, participants were about 24 years old, of Euro-Canadian descent, and had a minimum of three years of experience in higher education. Of the 19 participants, 14 agreed to participate in the study. This research complies with the University's established criteria regarding ethical use of data and data collection. To respect confidentiality of participants, synonyms are used.

\section{Data Collection}

Mindfulness was measured using the validated Five Factor Mindfulness Questionnaire (FFMQ), a 39-item survey. This self-reported questionnaire examines five facets of mindfulness: observing, describing, acting with awareness, non-judging, and non-reactivity (Baer, Smith, Hopkins, Krietemeyer, \& Toney, 2006; Baer et al., 2008). Items are rated on a five-point scale ( $1=$ almost never, $5=$ almost always). Observing reflects the tendency to notice or attend to internal and external experiences (\#11: "I notice how foods and drinks affect my thoughts, bodily sensations, and emotions"). Describing reflects the tendency to describe and label these experiences with words (\#37: "I can usually describe how I feel at the moment in considerable detail"). Acting with awareness refers to directing undivided attention to one's current activity (\#38: "I find myself doing things without paying attention"). Non-judging reflects a non-evaluative attitude towards inner experiences (\#35: "When I have distressing thoughts or images, I judge myself as good or bad, depending what the thought/image is about."). Non-reactivity is the tendency to allow thoughts and feelings to come and go, without getting caught up in them or react instantly to them 
(\#21: "In difficult situations, I can pause without immediately reacting"). To complement the FFMQ, an analysis of the practice logs and a two-page essay in which preservice teachers reflected on their experience with Mindfulness was undertaken. Qualitative analysis of the essay surfaced common themes identified by the preservice teachers.

\section{Results}

The effectiveness of the mindfulness university course on students' own level of mindful awareness and attention was examined by using the overall mindfulness scores of the pre and post results of the FFMQ. Table 1 demonstrates the pre and post results.

\section{Table 1}

FFMQ pre and post results

\begin{tabular}{|c|c|c|}
\hline Participant & $\begin{array}{c}\text { FFMQ } \\
\text { Pre }\end{array}$ & $\begin{array}{c}\text { FFMQ } \\
\text { Post }\end{array}$ \\
\hline 1 & 3.2 & 3.4 \\
\hline 2 & 2.8 & 3.5 \\
\hline 3 & 3.1 & 3 \\
\hline 4 & 2.8 & 3.2 \\
\hline 5 & 3.6 & 4.1 \\
\hline 6 & 2.5 & 3.1 \\
\hline 7 & 4.2 & 4 \\
\hline 8 & 3.2 & 3.8 \\
\hline 9 & 2.7 & 3.1 \\
\hline 10 & 2.7 & 3.6 \\
\hline 11 & 3 & 3.4 \\
\hline 12 & 2.9 & 3.1 \\
\hline 13 & 2.7 & 3.6 \\
\hline 14 & 3 & 3.7 \\
\hline
\end{tabular}

A qualitative analysis of the assignments was undertaken to uncover any common themes related to the impact of mindfulness practices. Three major themes emerged from the assignment. The first theme addressed the impact of the mindfulness course on educational practice. The second theme reflected the 
emotion regulation that preservice teachers were able to access, including elements of non-judgment and non-reactivity. The third theme emphasized the improved sense of well-being developed during the course. The following includes quotations from the participants' assignment.

\section{Improve Practice}

"I think more than anything, the practices that I have learned will really help me within my future teaching practice. I have noticed how much mindfulness can make a difference in my own life, and I want to bring mindfulness into the classroom and to my students as well." (Carol, course assignment, March 2016)

"I think I have gained tools and self-compassion that will help me continue my practice." (Kristin, course assignment, March 2016)

\section{Respond Instead of Reacting}

"My favourite practice is the pause practice. It allows me to manage my emotions and focus on the task at hand." (Marie, course assignment, March 2016)

"I have found that mindfulness practice has helped me to stay present in the moment which has reduced my anxiety. "(Nita, course assignment, March 2016)

"I have personally been able to recognize more about myself, my reactions verse responding, my thoughts, recognizing my feelings and emotions and my anger triggers." (Shaun, course assignment, March 2016)

\section{Well-Being}

"I have learned that mindfulness is a process, a journey to a deeper awareness and understanding of myself, of others, of all life, and perhaps inanimate objects too, in the interconnected universe. From the first session onward, there was a sense of calmness and non-judgment. I felt that the room was a safe place where I could gain insight into my being." (Ash, course assignment, March 2016)

"I always felt that starting the week on Monday's with class put my mind in a calmer, and focused head space for the remainder of the week." (Maya, course assignment, March 2016)

Students also self-reported on the extent to which they practiced the guided practices at home. All students course submitted their practice logs and commented on related guided practices (Pause, Sitting Practice, Body Scan, Mindful Eating, Mindful Movement). An overview of the rates of completion of the practice logs indicated that during the course of the nine-week program, practices were done with regular frequency: $90 \%$ did the daily practices and $10 \%$ did practices about three to five times a week.

Considering that the smartEducation course was being offered as a non-credit extension of the Teacher Education program and that attendance was not compulsory, participation in this class was high. Around $10 \%$ of the students attended a minimum of four to six sessions; the other $40 \%$ attended six or more of the sessions, with over $50 \%$ attending all eight sessions including the Silent Retreat. 


\section{Discussion}

The results of the FFMQ and the qualitative analysis of the assignments and the practice logs demonstrate that the level of mindful awareness increased during the smartEducation course. More specifically, improvement was mainly seen in being less judgmental and less reactive towards thoughts, feelings, and emotions of others and particularly of oneself. Participants self-reported modest increases in acting with awareness, along with modest decreases in practicum-related stress and time-management stress. The qualitative analysis of the assignment identified three major themes relating to improving practice, emotional self-regulation, and well-being. An overview of the practice logs indicated that a strong majority of participants adhered to the guided practices. These results are reflective of previously discussed empirical studies which emphasize the positive benefits of mindfulness-based initiatives like smartEducation on teachers' health and well-being. This qualitative data supports the quantitative findings (self-administered FFMQ) and reflects the benefits of introducing mindfulness strategies in Teacher Education programs and as professional learning for preservice and service teachers in order to cultivate the skills necessary to become aware of and to regulate thoughts, emotions, body, and behaviour to manage stress to improve health and well-being.

Considering that teaching is one of the professions most associated with high levels of stress and incidences of workplace burnout, the mental discipline necessary to follow guided practices can also function as a skill acquisition to induce plastic changes in the brain which, in turn, shape cognition, mood, and behavior. In other words, teachers' positive mood can contribute to positive classroom climate, which, in turn, supports student learning (Davidson et al., 2003; Taylor et al., 2015).

\section{Limitations}

This pilot study provided an overview of research supporting MBIs in pedagogical contexts and a qualitative analysis of a pilot study conducted with preservice teachers. Admittedly, due to the limited scope of the population and the summarily descriptive analysis of the FFMQ, the conclusions made did not necessarily provide substantial justification to move forward with MBIs as professional learning for preservice and service teachers. Results, however, were aligned with previous research (Montgomery \& Rupp, 2005; Roeser et al., 2012; Roeser et al., 2013; Taylor et al., 2015). Future research directions should include a larger more diverse population including gender and socioeconomic variables as well as an in-depth analysis of the five facets of mindfulness (observing, describing, awareness, non-judging, and non-awareness). Further follow-ups should be included at a six-week interval, then a six-month interval, and, finally, a yearlong interval. Despite these limitations, it is wise to cast a gaze at the literature which, in fact, calls for innovative, cost-effective ways for educational institutions to develop and support the resilience of teachers (Lantieri \& Nambiar, 2012; Meiklejohn et al., 2012; Roeser et al., 2012; Taylor et al., 2015). 


\section{Conclusion}

The pilot study contributes to a growing literature on the benefits of mindfulness practices aimed at educators (Jennings et al., 2009; Jennings et al., 2012; Meiklejohn, 2012; Roeser et al., 2012, 2013). The mindfulness-based initiative that is smartEducation shows promising results, suggesting that this enterprise may be effective as professional learning supporting preservice teacher candidates as they confront some of the stresses inherent in the teaching profession. While also supporting teacher wellbeing, the mindfulness skills developed in a professional learning oriented course like smartEducation can act as an important component of the prosocial classroom, ensuring the emergence of a culture of learning for all students. As previously stated, emerging research exploring the bidirectional relationship between classroom improvement and student improvement emphasizes how teacher social-emotional competence relates to both classroom climate and student outcomes. The literature points toward a link between teacher agency, prosocial classrooms, and psychosocial characteristics of teachers as important conditions for success.

\section{Future Directions}

Acknowledging the evidence-based nature of MBls, emergent research is also indicating that well-being can be positioned to promote creativity, capability, and productivity (Nielson, 2008; Seligman, 2002). Further derivatives of the non-credit smartEducation 20-hour course includes accredited variations at the undergraduate and graduate levels supported by scholarly and professional readings juxtaposed with creative and critical practices. Within this context, students are encouraged to explore different aspects of mindful engagement using arts-based practices. Examples of artistic artefacts are below.

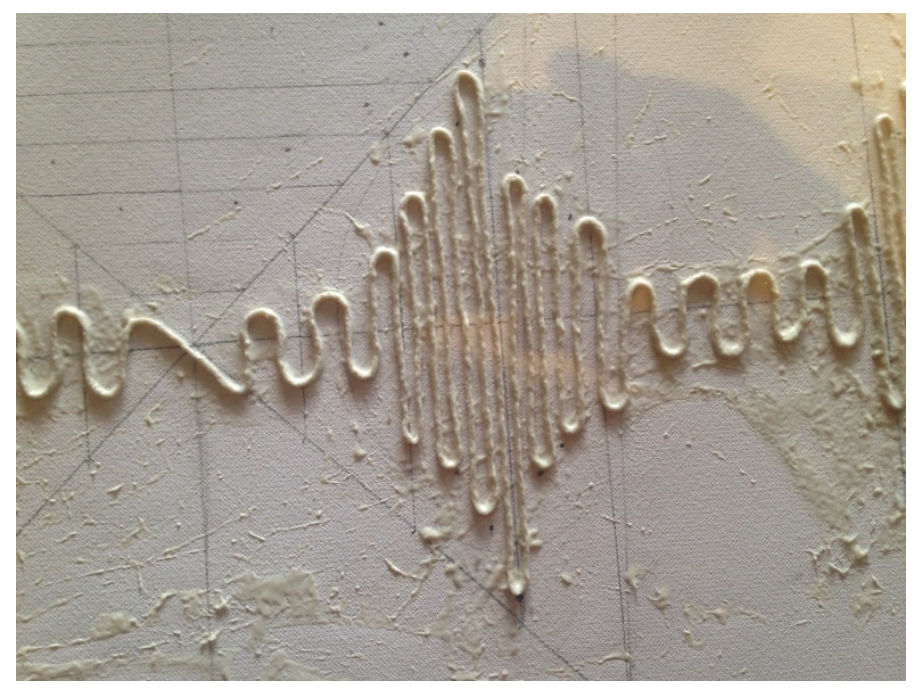

Fig. 1: Megan Briskham, course assignment 2016 


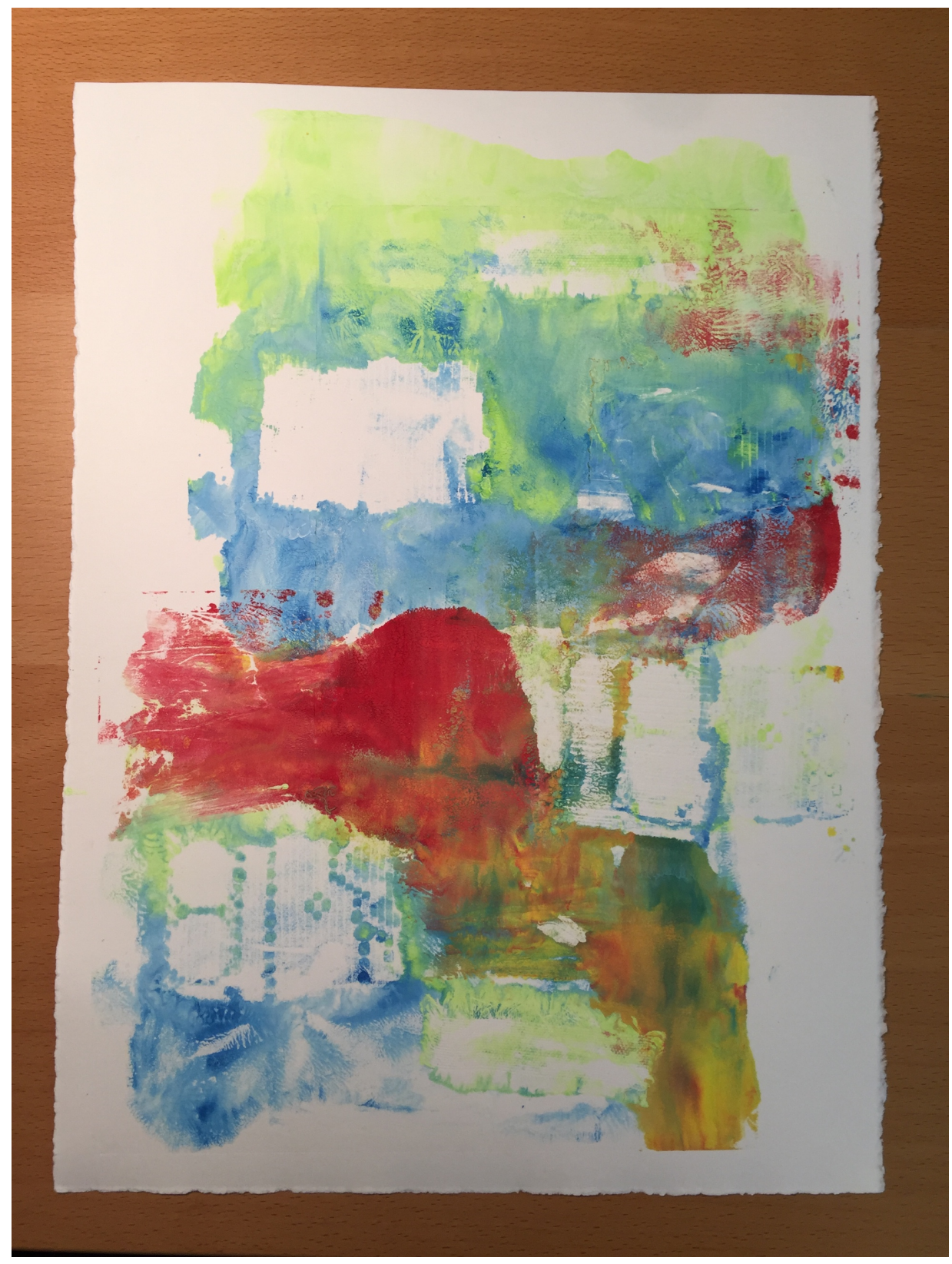

Fig. 2: Laura Wyllie, course assignment 2016

Reflecting on the import of the inner curriculum of classrooms, Lantieri and Nambiar (2012) acknowledge that the field of education must not only pay attention to the inner lives of teachers and students, but also give them the skills and strategies designed to cultivate skills that foster inner calm and resilience. Similarly, Goleman (2008), emphasizing the importance of social and emotional resiliency, supports the nurturing of mindful teaching and learning practices in educational contexts. By cultivating the potential of mindful awareness, the significant values of personal growth, learning, moral living, and caring for others are also nurtured (Ragoonaden, 2015; Roeser et al., 2012). 
Due to the positive results emanating from evidence-based research in Medicine and in Health, MBIs, like smartEducation, are being recognized as non-invasive health and well-being interventions in educational contexts (Mackenzie, 2015). To reiterate, many studies demonstrate that practicing mindfulness decreases occupational stress and compassion burnout and can positively contribute to overall well-being (Abenavoli et al., 2013; Flook et al., 2013). Since well-being as a state has been shown to significantly affect one's personal, social, and work lives, wellness programs should be given the opportunity to expand and grow in educational environments where the presence of stress can significantly and negatively influence practice and ensuing classroom culture.

\section{References}

Abenavoli, R. M., Jennings, P. A., Greenberg, M. T., Harris, A. R., \& Katz, D. A. (2013). The protective effects of mindfulness against burnout among educators. The Psychology of Education Review, $37(2), 57-69$.

Baer, R.A., Lykins, E. L. B., \& Peters, J. R. (2012). Mindfulness and self-compassion as predictors of psychological well-being in long-term meditators and matched non-meditators. The Journal of Positive Psychology, 7, 230-238.

Baer, R. A., Smith, G. T., Hopkins, J., Krietemeyer, J., \& Toney, L. (2006). Using self-report assessment methods to explore facets of mindfulness. Assessment, 13, 27-45.

Baer, R. A., Smith, G. T., Lykins, E., Button, D., Krietemeyer, J., Sauer, S., et al. (2008). Construct validity of the Five Facet Mindfulness Questionnaire in meditating and nonmeditating samples. Assessment, 15, 329-342. doi:10.1177/1073191107313003

Benn, R., Akiva, T., Arel, S., Roeser, R. (2012). Mindfulness training effects for parents and educators of children with special needs. Developmental Psychology, 48(5), 1476-1487. doi:10.1037/a0027537

Brown, K. W., \& Ryan, R. M. (2003). The benefits of being present: Mindfulness and its role in psychological well-being. Journal of Personality and Social Psychology, 84, 822-848.

Cullen, M. (2011). "Mindfulness-based interventions: An emerging phenomenon." Mindfulness, 2, no. 3: 186-193.

Cullen, M., \& Wallace, L. (2010). Stress management and relaxation techniques in education (SMART) training manual. Unpublished manuscript, Impact Foundation, Aurora, Colorado.

Davidson, R J., Kabat-Zinn, J., Schumacher, J., Rosenkranz, M., Muller, D., Santorelli, S., et al. (2003). Alterations in brain and immune function produced by mindfulness meditation. Psychosomatic Medicine 65, 4, 564-570.

Flook, L., Goldberg, S. B., Pinger, L., Bonus, K., \& Davidson, R. J. (2013). Mindfulness for teachers: A pilot study to assess effects on stress, burnout, and teaching efficacy. Mind, Brain, and Education, 7, 182-195. doi:10.1111/mbe.12026

Frank, J.L., Jennings, P.A, \& Greenberg, M.T. (2013) Mindfulness-based interventions in school settings: An introduction to the special issue. Research in Human Development, 10(3), 205-210. 
Goleman, D. (2008). Introduction. In L. Lantieri \& D. Goleman, Building emotional intelligence: Techniques for cultivating inner strength in children (pp. 1-4). Boulder, CO: Sounds True.

Greeson, J. M. (2009). Mindfulness research update 2008. Complementary Health Practice Review, 14(1), 10-18.

Jennings, P. A., \& Greenberg, M. T. (2009). The prosocial classroom: Teacher social and emotional competence in relation to student and classroom outcomes. Review of Educational Research, 79(1), 491525.

Jennings, T., Lantieri, L., \& Roeser, R. (2010). Supporting educational goals through cultivating mindfulness. Approaches for teachers and students. In P.M. Brown, M.W. Corrigan, \& A. HigginsD'Alessandro (Eds.), Handbook of prosocial behaviour (pp. 371-397). Rowman \& Littlefield: Lanham, Maryland.

Karsenti, T., \& Collin, S. (2013). Why are new teachers leaving the profession? Results of a Canada-wide survey. Education, 3(3), 141-149. doi:10.5923/j.edu.20130303.01

Kaser, L., \& Halbert, J. (2009) Leadership mindsets: Innovation and learning in the transformation of schools. Routledge: London.

Lantieri, L., \& Nambiar, M. (2012). Cultivating the social, emotional and inner lives of teachers and children. Reclaiming Children and Youth, 21(2), 27-33.

Lieberman, A. (1995). Practices that support teacher development: Transforming conceptions of professional learning. Phi Delta Kappan, 76(8), 591-596.

Ludwig, D. S., \& Kabat-Zinn, J. (2008). Mindfulness in medicine. Journal of the American Medical Association, 300(11), 1350-1352.

Lykins, E. L. B., \& Baer, R. A. (2009). Psychological functioning in a sample of long-term practitioners of mindfulness meditation. Journal of Cognitive Psychotherapy: An International Quarterly, 23, 226-241

Mackenzie, E. (2015). Mindfulness training. A transdisciplinary approach to assessing efficacy in education. In K. Ragoonaden (Ed.), Mindful teaching and learning: Developing a pedagogy of well-being. Lanham, MD: Lexington Books. An Imprint of Rowman Littlefield.

McCown, D., Reibel, R., \& Mecozzi, M. (2010) Teaching mindfulness: A practical guide for clinicians and educators. Springer Science+Business Media, LLC.

Meiklejohn, J., Phillips, C., Freedman, M.L., Griffin, M. L, Biegel, G., Roach, A., et al. (2012). Integrating mindfulness training into K-12 education: Fostering the resilience of students and teachers. Mindfulness, 3, 291-307.

Mockler, N. (2005). Transforming teachers: New professional learning and transformative teacher professionalism. Journal of In-Service Education, 31(4), 733-746.

Mockler, N. (2013). Teacher professional learning in a neoliberal age: Audit, professionalism and identity. Australian Journal of Teacher Education, 38(10).

Montgomery, C., \& Rupp, A. A. (2005). A meta-analysis for exploring the diverse causes and effects of stress in teachers. Canadian Journal of Education, 28, 458-486. 
Moran, J., William, K., \& Heatherton, T. (2013). What can the organization of the brain's default mode network tell us about self-knowledge? Frontiers in Human Neuroscience, 7, 1-6.

Nielson, T. W. (2008). Towards pedagogy of giving for well-being and social engagement. In Terence Lovat, Ron Toomey, \& Neville Clement (Eds.), International research handbook on values education and student wellbeing (pp. 617-630). The Netherlands: Springer.

Oberle, E., \& Schonert-Reichl, K.A. (2016). Stress contagion in the classroom? The link between classroom teacher burnout and morning cortisol in elementary school students. Social Science \& Medicine, 159, 30-37.

Palmer, P. (1998). Courage to teach: exploring the inner landscape of a teacher's life. San Francisco: Wiley.

Poulin, P. A., Mackenzie, C.S., Soloway, G. \& Karayolas, E. (2008). Mindfulness training as an evidencedbased approach to reducing stress and promoting well-being among human services Professionals. International Journal of Health Promotion and Education, 46(2), 72-80.

Ragoonaden, K. (Ed.) (2015). Mindful teaching and learning: Developing a pedagogy of well-being. Lanham, MD: Lexington Books: A Division of Rowman \& Littlefield.

Ragoonaden, K., \& Bullock, S. (Eds.). (2016). Mindfulness and critical friendship. A new perspective on professional development for educators. Lanham, MD: Lexington Books: A Division of Rowman \& Littlefield.

Roeser, R. W., Schonert-Reichl, K. A., Jha, A., Cullen, M., Wallace, L., Wilensky, R., et al. (2013). Mindfulness training and reductions in teacher stress and burnout: Results from two randomized, waitlistcontrol field trials. Journal of Educational Psychology, 2-19. doi:10.1037/a0032093.

Roeser, R.W., Skinner, E., Beers, J., \& Jennings, P.A. (2012). Mindfulness training and teachers' professional development: An emerging area of research and practice. Child Development Perspectives, 6(2), 167-173.

Saltzman, A. (2012). Mindfulness: A guide for teachers. Retrieved from http://www.contemplativemind.org/Mindfulness-A_Teachers_Guide.pdf

Schonert-Reichl, K. A., \& Lawlor, M. S. (2010). The effects of a mindfulness-based education program on pre-and early adolescents' well-being and social and emotional competence. Mindfulness, 1(3), $137-151$.

Seligman, M.E.P. (2002). Authentic happiness: using the new positive psychology to realize your potential for lasting fulfillment. New York: Free Press.

smartEducation Participant Booklet. (2015). Faculty of Education. The University of British Columbia.

Taylor, C., Harrison, J., Haimovitz, K., Oberle, E., Thomson, K., Schonert-Reichl, K., et al. (2015). Examining ways that a mindfulness-based intervention reduces stress in public school teachers: A mixed-methods study. Mindfulness, 7, 115-129.

Timperley, H. (2008). Teacher Professional Learning and Development. International Academy of Education. International Bureau of Education. Education Practice Series, 18, 1-23. 
Zeichner, K. (1995). Beyond the divide of teacher research and academic research. Teachers and Teaching: Theory and Practice, 1(2), 153-172.

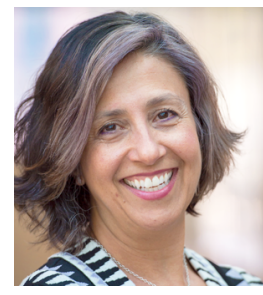

Karen Ragoonaden is a faculty member in Education at UBC's Okanagan campus. Her work in the conceptualization and development of the smartEducation program focuses on integrating mindfulness initiatives in education (MBI). The sessions, conceptualized as non-credit and accredited courses, aim to develop and sustain the health and well-being of professionals in educational and therapeutic contexts. An ancillary aim of this $\mathrm{MBI}$ is to implement mindfulness programs in several sectors, promoting a network of collaborations, and sustainable practices. Linked with research expertise across disciplines, derivatives of smartEducation include smartNursing and smartUBC. 